\title{
Resenha do Livro La Fura Dels Baus em quarentena, quarenta anos de trajetória grupal: 1979-2019
}

\section{Book Review La Fura Dels Baus in quarantine, forty years of group trajectory: 1979-2019}

Maria Amélia Gimmler Netto ${ }^{1}$ 


\section{Resumo}

La Fura Dels Baus en Quarantena 40 anys de trajectória grupal: 1979-2019 é um livro que foi lançado em Barcelona, na Espanha, em comemoração aos quarenta anos da companhia teatral catalã. Composta por sete capítulos a publicação dispõe também de conteúdo interativo. O histórico do grupo, seu repertório, processos de criação e de transmissão de conhecimento são abordados por Mercè Saumell que é investigadora e professora do Instituto de teatro de Barcelona. Esta resenha enfoca especificamente os aspectos referentes à remontagem do espetáculo Manes, às metodologias de criação do grupo e às noções de formação e investigação em artes cênicas.

Palavras-chaves: Grupo teatral; metodologias de criação; formação em artes cênicas; remontagem de espetáculo; Investigação em artes cênicas

\section{Abstract}

La Fura Dels Baus en Quarantena 40 anys de trajectória grupal: 1979-2019 is a book that was launched in Barcelona, Spain, in celebration of the forty years of the Catalan theatre company. Consisting of seven chapters, this publication also shows interactive content. The group's history, repertoire, processes of creation and knowledge transmission are approached by Mercè Saumell, who is a researcher and teacher at the Barcelona Institute of Theatre. This review focuses specifically on aspects related to the recreation of the play Manes, the group's creation methodologies and the notions of training and research in the performing arts.

Keywords: Theatre group; creation methodologies; training in the performing arts; recreation of plays; performing arts research

\footnotetext{
${ }^{1}$ Profa. Ms. Curso de Teatro Licenciatura - Universidade Federal de Pelotas (UFPel). Investigadora visitante no Centro de Ciências Humanas e Sociais de Madrid/ Espanha e Bolsista capes Print/UFBA 2019/20. mamelianetto@gmail.com
} 


\section{Resenha da obra:}

SAUMELL, Mercè. LA FURA DELS BAUS EN QUARENTENA. 40 anys de trajectória grupal:1979-2019. Próleg per La Fura dels Baus. Barcelona: Angle Editorial, 2019.
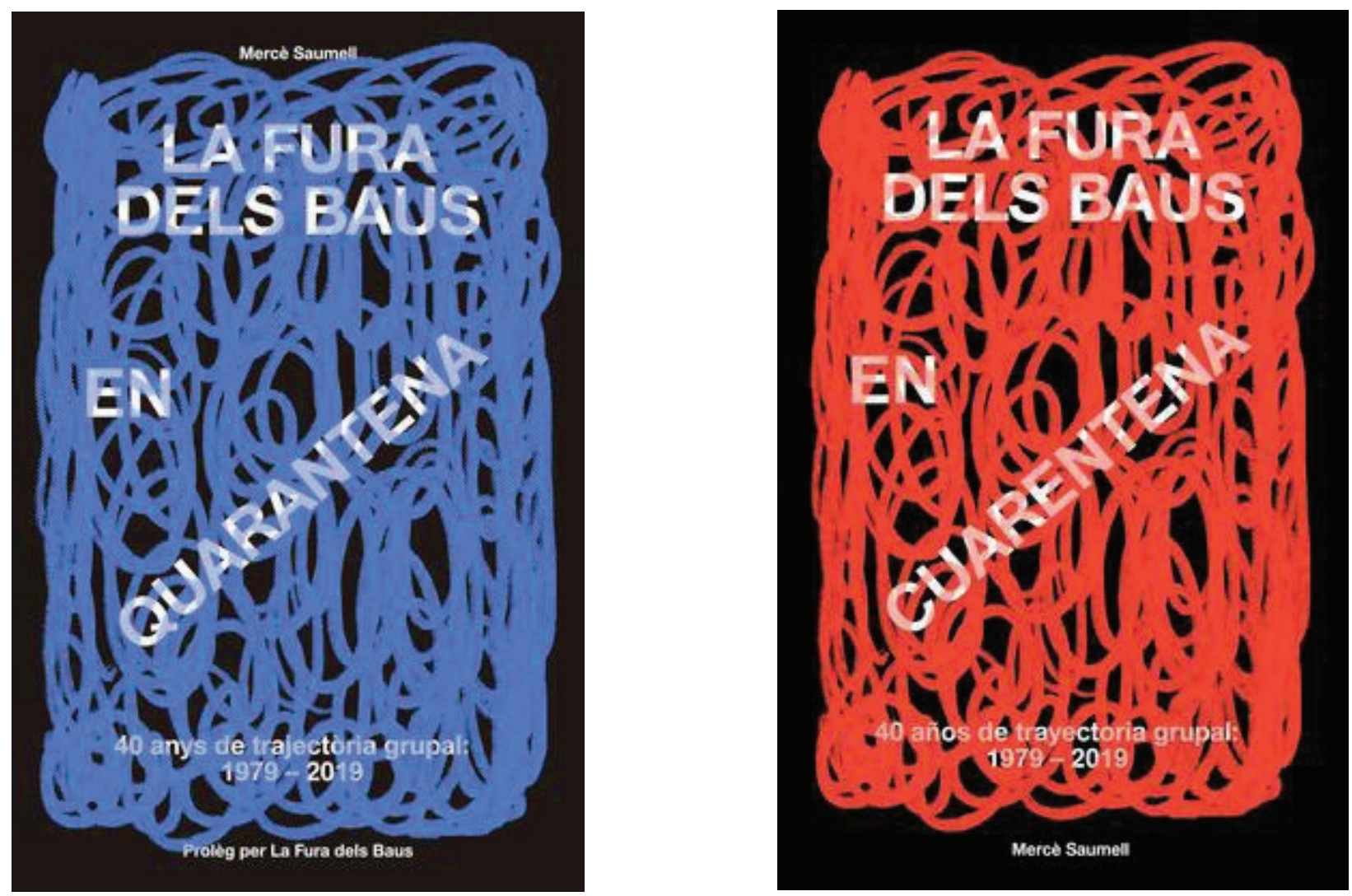

E-ISSN: 2358.6958 
La Fura Dels Baus en Quarantena - 40 anys de trajectória grupal: 1979-2019 (ISBN: 978-84-17214-74-6), teve sua primeira edição lançada em outubro de 2019 em Barcelona pela Angle Editorial e La Fura Dels Baus. Com autoria de Mercè Saumell a publicação está no idioma catalão e é uma brochura de aproximadamente duzentas páginas com projeto gráfico/diagramação de Francisca Torres.

O livro dispõe de conteúdo interativo em formato de vídeo. Para ter acesso a este conteúdo é necessário baixar um aplicativo gratuito na App Store ou no Google Play e se necessita dispor de acesso à internet. Algumas das imagens do livro possuem um símbolo, que é uma seta preta ao lado ou abaixo, para identificar a presença do conteúdo interativo.

O índice, ou sumário do livro, apresenta sete capítulos acrescidos de Epílogo, Bibliografia, Discografia, Videografia e webs, além de um Histórico do La Fura Dels Baus. Há também uma breve apresentação da autora, além de uma sessão intitulada de Prólogo composta por trechos assinados por Àlex Ollé, Carlus Padrissa, Jurgen Muller, Miki Espuma, Pep Gall e Pera Tatiñá, artistas integrantes da companhia catalã. Os sete capítulos do livro são: 1) Primeira Etapa: duas trilogias Fureiras; 2) Mudanças e permanências. Metodologias de criação; 3) O espaço público: propostas de rua e macroespetáculos; 4) La Fura Dels Baus e a Ópera; 5) Propostas de sala (indoor); 6) Transmissão de conhecimento. Formação e criação; 7) La Fura Dels Baus como objeto de estudo.

Esta resenha enfocará especificamente aspectos referentes à remontagem do espetáculo Manes (primeiro capítulo), às metodologias de criação (segundo capítulo) e às noções de formação e investigação em artes cênicas (sexto capítulo).

\section{Repertório e Criação - A recriação de Manes}

Manes (1996) foi o último espetáculo da segunda trilogia Furera, ele fechou um ciclo criativo e, sendo assim, possuía referencias temáticas já desenvolvidas pela companhia, como a comida, o sexo, a vida e a morte. Manes é uma proposta cênica que não se baseia em um texto dramático, mas sim na ação em cena. A noção de tempo correspondia ao ritmo da peça e não a sua narrativa, e com essa peça o grupo colocava, mais uma vez, a expectativa do público frente a um aparente caos cênico. O espaço onde se desenvolviam as ações era concebido de maneira assimétrica, de difícil controle pela percepção e olhar do público e a luz se diversificava em diferentes atmosferas, evocando em alguns momentos um ambiente Disco Club. Manes também vem a ser o primeiro espetáculo fureiro de autoria, assinado por Pera Tantiñá. Esta encenação, de dimensões mais reduzidas que as anteriores da companhia, chamava a atenção por seu caráter mais artesanal e, para isso as dimensões da produção foram planejadas para que fosse possível se fazer uma turnê usando apenas uma caminhonete.

$\mathrm{Na}$ atualidade Manes é um caso singular de recriação no teatro catalão. A peça foi remontada em 2019, na ocasião da comemoração dos 40 anos do grupo. Para Tantiñá, voltar a levantar o espetáculo significa recuperar a essência do ritual fureiro para as novas gerações. Em Manes se destacam as emoções puras, primárias, a partir de uma proposta simples, muito energética e baseada na interpretação. Ela é arte- 
sanal e analógica, sem a presença da tecnologia digital. A autora do livro considera que seria bem interessante fazer uma comparação entre a recepção da montagem de 1996 e a que foi feita depois de 2018.

\section{Metodologias de criação - colaboradores, satélites e tecnologia}

O grupo, em seus projetos criativos, sempre pôs em tensão os limites entre as disciplinas ao buscar, por exemplo, a participação de filósofos na composição da dramaturgia, diretores de cinema, engenheiros robóticos e informáticos, ou chefs de cozinha. Para o artista Àlex Ollé, o trabalho do colaborador envolve uma especialização criativa e, também, a permeabilidade da equipe e exemplifica com a presença de um desenhador de luz que pode trazer uma ideia de matéria dramatúrgica, num processo de convivência criativa.

La Fura Dels Baus podem ser considerados criadores de teatro no sentido ontológico do termo, pois o entendem como uma vivência coletiva entre intérpretes e espectadores. Eles mesmos se afastam de uma possível polemica que os coloca fora do teatro pelo protagonismo da tecnologia em suas propostas. Em relação ao uso de tecnologias em cena o grupo é um dos pioneiros a introduzir recursos como aplicativos para uso do espectador, considerado multitasking, por sua atitude multitarefa identificada com as novas gerações. O grupo investe assim em um salto geracional considerando a percepção da nova geração que está habituada a manipular muita informação de maneira simultânea.

O convívio criativo entre colaboradores com suas diferentes especialidades, para a realização de um determinado trabalho cênico, abre espaço também para a criação de outros produtos. Os artistas do grupo denominavam Satélites a aqueles produtos que surgiam a partir de seu eixo criativo que são os espetáculos fureiros. Os satélites eram os concertos, as exposições, os discos, os vídeos. Esta ideia de criar satélites é a de traduzir o material cênico para outro suporte, uma prática habitual para - La Fura Dels Baus. Também, a incorporação da tecnologia digital mais sofisticada aos espetáculos, que ocorreu com o passar das décadas, significa um aumento do círculo de colaboradores e ao mesmo tempo novos desafios e possibilidades criativas inesperadas até então pelos diretores fureros. Ainda assim na atualidade, alguns membros do grupo continuam usando o desenho como ferramenta criativa. Porém a maioria das propostas já costuma ser preparada na frente do computador, para então se confeccionar um dossiê que apresenta a perspectiva criativa, a visualização dos elementos de cenário e de figurino e os detalhes técnicos da montagem.

No início dos trabalhos da companhia a autoria costumava ser compartilhada. O que importava era a livre circulação de ideias e de como elas se resolviam na prática criativa coletiva. O método de criação se assemelhava à criação coreográfica e se distanciava, portanto, dos procedimentos teatrais tradicionais de criação de cenas a partir de um texto escrito. O processo de criação do grupo era de caráter lúdico e compartido, sem assinaturas. Também não havia a necessidade de um discurso teórico elaborado: o discurso era a própria ação cênica. As ações que haviam sido escoIhidas se sobrepunham com a finalidade de gerar narrativas mais complexas, criando estruturas e, ao mesmo tempo, uma metodologia própria baseada na experiencia. Os 
seus espectadores, desde os primórdios recordam haver experimentado uma forma de caos, uma sensação de risco. A autora do livro salienta que o que existia realmente era um risco estético, não físico e que a prova disso é o fato de que eles, os artistas fureros nunca sofreram um acidente grave em cena.

Depois de quarenta anos de trajetória, os diretores fureros são expertos em modelar o espaço de maneira muito orgânica e também de orquestrar as diferentes linguagens como a gestual, a sonora, a videográfica, entre outras, como se tudo fosse um processo sinestésico, friccionando os potenciais visuais, sonoros e espaciais de cada elemento que é incorporado ao processo. Os diretores fureros são quem marca o ritmo e os demais criadores vão se adicionando às dinâmicas já postas em marcha.

Sendo assim é o espaço cênico o primeiro suporte da ferramenta metodológica criativa, mais do que a geração de emoções por parte dos atores. Não é de se surpreender que o núcleo de colaboradores habituais da companhia tenha mais relação com o espaço do que com a interpretação, sendo eles escultores, engenheiros, cenógrafos, videoartistas, arquitetos, entre outros. Ainda assim, existem atores colaboradores que já trabalharam diversas vezes com a companhia, embora o mais habitual seja que eles contratem profissionais através de seleções de elenco. Dos artistas fundadores, Jurgen Muller foi o último a abandonar a cena como ator. Saumell considera que ele e Álex Ollé são, talvez, os artistas do grupo mais interessados no universo interpretativo, tanto no teatro como na ópera.

\section{Investigação e Formação em artes cênicas}

Movidos pelo desejo de saber como funcionam os procedimentos de criação em arte, criadores, docentes, investigadores e estudantes rastreiam arquivos, indagam sobre o processo criativo, sobre os modos de fazer e pesquisam as genealogias artísticas. Talvez porque ferramentas criativas antes entendidas como segredos individuais, agora deixaram seu lugar para experiências de criação colaborativas e interdisciplinares. Dentro desta realidade se está reformulando a educação e no centro deste debate estão as metodologias criativas, noção esta que ganha interesse até mesmo para o produto cênico final.

É inegável que algo está mudando na aprendizagem das artes cênicas e o mais interessante desta transformação é que a própria transmissão de conhecimentos passa a conter elementos performativos, de encenação e, no caso do teatro, a arte em si é forma final e método ao mesmo tempo. Desta maneira se podem estabelecer protocolos de transmissão de conhecimento que formam parte de projetos criativos, como se fossem catalizadores poéticos e, também, ativadores de diálogo entre gerações. Sendo assim, estas novas formas de entender as artes cênicas repercutem, igualmente na forma de ensiná-las.

As metodologias teatrais se aplicam reincidentemente a outros campos de estudo. Atualmente se estabelecem áreas de colaboração entre teatro e educação, teatro e medicina, teatro e tecnologia ou teatro e urbanismo, entre outras. Conceitos como emoção, ficção, jogo e empatia, vinculados secularmente ao teatro, são maleáveis para a transmissão fora de seu contexto original por abrirem-se a outras disciplinas. Estes projetos colaborativos estimulam a criatividade e a inovação e o 
enriquecimento mútuo entre áreas de conhecimento. E não somente são uteis para o desenvolvimento profissional no ambiente das artes cênicas, mas sim para todos os participantes, provenientes de outros setores, através da aprendizagem experiencial, a experiência vivida.

A partir da prática da fricção furera - ou seja, do aprendizado que se dá pelo atrito da troca de experiencias entre colaboradores - desde a época inicial do coletivo, os seus membros expandiram aquele genuíno método de criação para outros artistas, colaboradores habituais ou ocasionais, a partir de um frutífero princípio de contaminação mútua. Princípios estes que contam também com um genuíno respeito aos processos de aprendizagem que se dão em ambiente criativo, abrindo-os aos participantes de worshops ou oficinas, seminários e outras iniciativas de formação. A companhia percorreu uma larga trajetória neste sentido, desde os primeiros workshops iniciais, ministrados por seus diretores em festivais e seminários, até recente inauguração da Fundació Epica, em 18 de dezembro de 2018. Uma entidade sem fins lucrativos que se constitui em um espaço de aprendizagem multidisciplinar voltado para as artes cênicas, situada na antiga fábrica de móveis Rojas de Baladona. O trabalho a ser desenvolvido por esta recente fundação busca entender o processo criativo como um catalizador entre arte, ciência e tecnologia.

Muito vinculado à aprendizagem experimental, o conceito de laboratório vinculado às artes cênicas se forma ao longo do século XX. Segundo Saumell, a associação entre teatro e laboratório não é nova. Ela invoca aquele lugar onde se pode falhar e ao mesmo tempo se aprender com os erros. Esta atitude de experimentação e de transmissão de metodologias criativas próprias também vai acompanhar o trabalho de algumas companhias teatrais importantes surgidas na Europa nas décadas de sessenta e setenta. O Thèatré du Soleil, dirigido por Ariane Mnouchkine na França, Jerzy Grotowski com seu Teatro Laboratório na Polônia e depois na Itália, ou ainda o Odin Theatre, liderado por Eugenio Barba, na Dinamarca. A autora considera natural que o catalão La Fura Dels Baus, depois de quarenta anos, crie um laboratório que vise transmitir sua prática teatral abrindo-a para outras disciplinas.

A companhia catalã, de maneira intuitiva, sempre baseou suas propostas docentes e de investigação na experiencia como veículo de conhecimento. A colaboração e o trabalho em equipe, fatores que favorecem a criatividade e que foram postos em prática pela companhia desde sua origem, são conceitos fundamentais para esta metodologia. Estas características alinham-se, também, com as correntes metodológicas mais inovadoras de ensinamentos artísticos. A ferramenta básica nesta perspectiva é a ação corporalizada, ao que os anglo-saxões denominam por embodiment. Esta maneira de compreender a transmissão de conhecimento a partir da experiencia se enlaça com a prática artística como metodologia de investigação, também aplicada à docência e conectada internacionalmente com a noção de Practice as Research que, conforme Saumell nasceu na Escandinávia nos princípios dos anos vinte e começou a ser praticada, quase em paralelo, na Grã-Bretanha, nos EUA e no mundo acadêmico anglo-saxão. Nesta metodologia, ainda pouco desenvolvida na Espanha, se busca uma continuidade entre fazer-refletir-articular-fazer, em um ciclo que se inicia e acaba na ação. Assim sendo, a experiencia e o feito de experimentar se incluem dentro do saber, já que se incorporam conceitos como imaginação, jogo ou 
prazer em termos de igual para igual com a pesquisa de documentação, o desenvolvimento de visão crítica e a reflexão.

\section{A autora do livro e seus futuros leitores}

Mèrce Saumell é doutora em História da Arte com uma tese sobre as companhias teatrais catalãs. Já deu aulas nas Universidades de Salamanca e Girona e agora é professora do Instituto de Teatro de Barcelona. Ela participa de diversos projetos de pesquisa de âmbito internacional e regional, é autora de livros e artigos especializados na área das artes cênicas e já participou de cursos e conferências na Finlândia, Lituânia, Brasil, Chile, Alemanha e Irlanda. O grupo catalão La Fura Dels Baus é um de seus temas de estudos principais.

O livro La Fura Dels Baus em quarentena (1979-2019) além de estudar as metodologias coletivas de criação, enfoca a consolidação de novos discursos cênicos. Ele também não deixa de ser uma biografia do grupo, lidando com acontecimentos cênicos como o impacto de suas primeiras propostas artísticas, a sua passagem pelas cerimonias olímpicas e as suas encenações de óperas e produções online. Seis de seus primeiros membros continuam desenvolvendo suas próprias linhas de trabalho e suas capacidades de risco e de contágio criativo proporcionaram a eles um amplo reconhecimento internacional entre público, critica e, também, para a pesquisa acadêmica. Para tanto, a leitura deste livro é altamente recomendada para todos profissionais das artes cênicas, professores, estudantes e espectadores, enfim para todas pessoas que reconhecem na experiencia das artes cênicas a sua potência de prazer e empatia, de emoção, conhecimento e aprendizagem.

\section{Referência}

SAUMELL, Mercè. LA FURA DELS BAUS EN QUARENTENA. 40 anys de trajectória grupal:1979-2019. Próleg per La Fura dels Baus. Barcelona: Angle Editorial, 2019.

\section{Recursos Eletrônicos}

https://www.lafura.com (visitado em novembro de 2019)

Diccionario Español by Farlex. App compatible with Iphone. Versión: 2.0. Copyright 2003-2019.

Traductor Softcatalà. Marcos Grau developer. App compatible with Iphone. Versión: 3.2. Copyright Softcatalà 2011.

Recebido em: 02/12/2019

Aprovado em: 05/12/2019 